\title{
DENTAL SERVICE FOR THE OTHER EIGHTY PER CENT.
}

\author{
By Guy S. Millberry, D.D.S., San Francieco, Cal. \\ (Read before the National Dental Association at Its Twenty-third Annual Session, New Orleans, La., \\ October 20-24, 1919.)
}

$\mathrm{S}$ OME enterprising person by mathematical calculation, if not by mathematical accuracy, has determined that eighty per cent of the people of America do not receive dental service. While statistics are conceded to be the life-blood of any health movement, we are, nevertheless, weary of reading the reports of investigations of our school population thruout the land indicating that no reduction in the prevalence of dental disease is being accomplished by the dental profession, except in a few isolated instances. I take it that this is our problem and no argument can be pursued until certain premises are submitted upon which we may all agree.

1. The two most important things in life are food-energy and man-power, and the greatest human problem is to convert food-energy into man-power in an economic and efficient manner.

2. Sound teeth and a healthy mouth are necessary to the conversion of foodenergy into man-power, and, therefore, dental service is either essential or incidental to this great human problem.

3. One hundred per cent of the people above the age of three years, except the edentulous dentureless cases, need dental service at least twice a year.

4. The best means of preventing dental disease and its systemic sequela, is by practicing mouth hygiene.

Will you grant these premises?
There must be some reason why a very large proportion or our population does not receive dental service. Being a self-obsessed as well as a self-made profession, we have not studied this problem and have given little thought to those who, thru fear, ignorance, lack of facilities, or lack of funds, have been unable to avail themselves of dental service. Our practices have been builded by a system of elimination. The undesirable and non-productive element, serving as a hindrance to our financial betterment, has been gotten rid of. This is not an unusual thing in the economic world for it is considered good business in the mercantile and manufacturing industries, in animal husbandry and agriculture, but what of the discards in the field of medicine.

Desirable and dependable agencies for the prevention and treatment of dental disease are wholly inadequate and, therefore, some other means must be employed for public health in paramount to all other things. Witness the recent pandemic of influenza.

Can we continue to advocate measures for the alleviation of human ills and absolve ourselves from the responsibilities of providing them? Have we no obligations to society, humanitarian if not economic, collective if not individual?

Should we not place the resources and blessings of dentistry within the reach of 
all classes of society? Unless the dental profession is willing to attack and solve these problems, some one will unquestionably undertake the task for us, and perhaps not wholly to our liking, nor for the best interests of the nation. With these thoughts before you, may I presume to offer a means to that end.

Three things are necessary:

1. Service.

2. Facilities.

3. Publicity.

\section{SERviCe.}

It is an acknowledged fact that there are not enough dentists to provide dental service for our population. In fact, there are not enough dentists to provide service for our school population. If we believe this, then the first essential is to provide more dentists, or provide for a division of labor whereby the well-trained dentists will be able to employ and direct the activities of more than one person, in order to provide more service for the people who choose to command his services. This means the employment of assistants, hygienists, mechanics, and secretarial service. While this is followed in a few localities with success, it is not the usual plan, and it may well become a new order of procedure, thus establishing a precedent for the young men being trained in our institutions today who will be your successors a decade hence.

Our institutions of learning must be subsidized and developed to train more men for dentistry, with auxiliary courses for hygienists and mechanics, just as our medical schools and hospitals are providing assistance for our medical colleagues by training nurses and technicians. Subsidies for the support and maintenance of such institutions may come from the state or from private endowment, the former by taxation, a more democratic way, the latter by gift or by adopting measures now being advocated by men of broad humanitarian beliefs who are diverting a part of the profits of patent royalties, or corporation or commercial enterprises into channels for the public good.

Scholarships must be provided so that the youth of our country who are financially unable to pursue this vocation, for which they may be equally as well fitted as their more richly endowed associates, will be given an equal opportunity. The largest proportion of the matriculants in our dental schools enroll as the result of a favorable contact or association with some dentist. Therefore, the diverting of more of the youth of our land into these professional channels rests with you in helping to supply the service so badly needed by the other eighty per cent.

\section{Facilities.}

In private practice men are now inclined to limit their practice to the accomplishments of one pair of hands. Some men will continue to practice in that way. If, in the course of events, it is deemed advisable to expand the facilities in private practice, it can be accomplished in two ways.

First, by training the student in such economic policies during his college residence so that he may become familiar with such procedures, and second, by providing the opportunity for employment in your offices for the recent graduate, until such time as he may become an associate with you or engage in practice for himself.

Increased facilities for private service mean a larger responsibility. The labor should carry its own overhead expense and a fair margin of profit, the distribution of which must include a proportionate amount for your responsibility and business acumen. Excessive profits on labor will result in an inharmonious relationship between you and your employees which, otherwise, might prove mutually advantageous. The guaranteed income with a profit-sharing plan is the 
best incentive to good work and the young graduate of today will welcome such an opportunity. Such a plan will give service to a certain portion of the discards, an advantage to themselves and the profession.

A large number of our people, however, must be cared for by means of a group plan: i. e. by the establishment of public dental dispensaries conducted on a self-sustaining basis but not for profit. To begin with, such offices must be subsidized by the state, county, or municipality, or by private endowment, in order to become established, tho such subsidies may be returned from a sinking fund provided in the plan. Dispensaries on the basis of voluntary service are passing, chiefly because adequate honest service to patients is the primal factor and to maintain this constantly, a proper remuneration for professional service must be established. This group plan makes the economic position of the young professional man much more stable, and his opportunities for professional study and advancement are larger.

Legislation looking toward that end successfully passed the California Legislature this year but it failed to received the Governor's approval.

Briefly the plan is this: In communities able to sustain them, there may be established, offices with from three to ten chairs, with the necessary additional equipment. In the larger cities several ten-chair offices may be established in different localities. Each of the larger offices will maintain departments for plate prosthesis, crown and bridge prosthesis, general operative work, extraction and surgery, radiography, orthodontics, and mouth hygiene and prophylaxis. Men and women whose capabilities or inclinations lead them into any of these fields will be employed.

Managed by a competent director with a personnel of dentists, dental hygienists, dental mechanics, office, clerical and social service assistance, the dispensary can be operated on a cost basis with a budget system just as successfully as any other enterprise. The details of adequate salaries on a graded scale, fees, audits, purchasing and collections together with publicity of an ethical nature may be carefully worked out.

To the public, such a plan would mean honest dental service at a reasonable fee. It would mean truthful information as to the care and conservation of the teeth. It would mean a higher standard of public health with a reduced cost to the taxpayer. Service in such dispensaries could be limited to that group of persons whose income now or at any time in the future is so small that private dental service is out of the question and therefore no dental service is received. Social service will limit this group just as it does in all large organizations today.

To the exiployees it would mean that the dentists just graduating from college, who are broke or those migrating from other places, may find employment and an opportunity to choose the type of dental work they wish to perfect themselves in, as well as a city in which they may choose to locate. During the period of employment they will naturally form social acquaintances, who, with the patients that may come to them either from or thru the dispensary, will enable them to engage in practice there or they may choose to go to another city until they find the opportunity they desire.

It would afford steady and well-paid employment for the dentist who has not sufficient business acumen to conduct an independent practice, as well as those who prefer salaried positions to the hazards of general practice. Properly safeguarded, and in cooperation with the State Board of Dental Examiners, it would provide an opportunity for licentiates from other states to gain employment under proper supervision pending the examinations or during the interval between them. Such a plan might ultimately assist in adjusting the difficulties 
now existing in reciprocal lisensure. To the other employees it would mean regular employment in terms equal to their qualifications and efficiency.

For the dental profession it would provide an opportunity for community service in the interests of humanity by shaping and directing the policies in dental practice for society in general at no great sacrifice of time. Such dental dispensaries as are proposed should be linked up with the dental societies in all states and counties, with active committees cooperating with the directors in each community.

It would offer an opportunity to shape the destinies of the young men just out of our school who, thru necessity, are obliged to seek employment, and who very frequently find their way into an environment which knowledge and experience tell us is not the most desirable. It would also mean that a place is available for referring that class of practice so frequently discussed in your offices, the persons whom you are asked to consider but those incomes or social position do not justify the payment of the fees required in private practice. They need dental service and constitute a large part of the other eighty per cent.

\section{Publicity.}

Since ignorance is one of the principal reasons why four-fifths of our population does not receive dental service then education is the antidote, and since most people receive their advanced education thru the daily press, then the best means of education is thru such channels. To quote $\mathrm{Mr}$. Chester H. Rowell, editor of the Fresno (Calif.) Republican, in a paper presented before the Pacific Division of the American Association for the Advancement of Science:1 "Medical science, because it is subject to hostile controversy, stands particularly in need of publicity, not merely as to the results but as to methods." And again, "It may be-

\footnotetext{
${ }^{1}$ Science. August 15, 1919.
}

come the duty of the American, even at the cost of some repugnant self-exploitation to make himself (or his profession) personally respected by the democracy. It cannot be done in the laboratory and in the scientific journals alone."

If there is any phase of human activity where ignorance or a little knowledge is a source of danger it is in the field of hygiene and public health. A plan of publicity, truthful in expression, lucid in character, and comprehensive in scope will be a necessary part of this service. First, it will be the means of educating the public as to the importance and value of honest dental service and will relieve the dentist in private practice of the financial responsibility of carrying on this dental propaganda for clean teeth and a healthy mouth, yet giving him an indirect control thru the committees appointed by his society, working with the director. Secondly, it will purposely and particularly tend to stimulate the demand for dental service to sustain the dispensaries.

If we can agree upon the four premises previously mentioned, viz., that the important things in life are intimately associated with the mouth and teeth and that the majority of the people are entitled to dental service looking toward the prevention of dental disease, then we must be prepared to change the existing order of things in dentistry in part at least.

Much has been said regarding this problem. Thoughts and ideas have been paraded in philologic array, much as human kind, uniformly constructed, is dressed in a wide variety of modes and costumes. Action, however, seems to have been submerged beneath waves of words. Optionated men find it difficult to reconcile their views to changed conditions, but the old order is changing and we must endeavor to meet the problems as they come to us now, not as they were a decade ago.

Adverse criticism ranging from a 
charge of violating the Code of Ethics to an effort to control the practice of dentistry thruout an entire state, has not modified the writer's opinion that some means must be provided to furnish honest dental service for the other eighty per cent, which shall be:

1. Primarily preventive in character.

2. Restorative and Corrective where necessary.

3. Available in terms of the means of the individual and at times or under conditions which will not impair his income.

4. Conveniently accessible to the majority.

5. Supplemented by truthful information, and divorced absolutely from charity.

\section{Discussion:}

\section{E. L. Pettibone, Cleveland, Ohio.}

The essayist has made no mention of the newest agency in caring for the other 80 per cent, the industrial dental dispensary. These dispensaries are multiplying very rapidly and altho they appeal to the employer as a means of increasing efficiency and cutting down the labor turnover, they are acting as a very great aid to good health by the farreachingness of their educational value in disseminating mouth hygiene knowledge. There are now seventy-two firms in the United States having one or more dental dispensaries and the number will, we believe, be doubled each year.

$\mathrm{We}$, in Cleveland, gave up the idea many years ago of trying to educate adults in mouth hygiene. The only way to educate any considerable portion of the public to mouth hygiene, or any other branch of preventive medicine, is by education of the children in the elementary, schools.

We began this in Cleveland with the last generation and dentistry or mouth hygiene needs very little publicity-especially of the newspaper variety-in our city.

We have: quite adequately provided for most of the other 80 per cent too.

The Board of Education conducts six dental dispensaries within the public school buildings. The Public School physician examines all children's mouths at the time of the general physical examination; notices of defects and needed treatment are sent to the parents with information that if parents are unable to pay, they can have free treatment at the dispensaries. The Cleveland Mouth Hygiene Association, one of 67 participating agencies of the Cleveland Welfare Federation, maintains three dental dispensaries located in three of our seven health centers which are under the Division of Health of the City of Cleveland.

In these dispensaries, we care for the children attending parochial schools and certain adults, especially tuberculous people, who are being allowed to remain in their own homes.

It is the style to clean your teeth in Cleveland and there is a very great improvement in the mouths we see today and those that came to us ten years ago.

Our School Board found out many years ago that it cost ten times as much to carry a child over a year as it did to fix his teeth and they are so limited as to funds that they employ every sensible means to save money and they consider our dispensaries such a means.

After January 1, 1920, dental supervision of all school children will be required by law in Ohio.

The legislature of West Virginia last year passed a law providing dental dispensaries for the school children of McDowell County. This law provided that the expense be borne by the taxpayers and that they should have a referendum election on it. The election carried by a large majority and over 
twenty dispensaries are being established.

Why not try that for your other 80 per cent? It will eliminate it entirely in ten years. (Applause).

Prof. C. E. Turner, Boston.

I certainly appreciate the willingness of your chairman and your section to listen to a man who is not a dentist, but only a mere professor of public health. I have thoroly enjoyed the clear presentation and the valuable discussion in this paper and in the comment which has already been made upon it, and as a member of the public health profession I want to say that we, as workers in this field of prevention, have a very high esteem for your profession, and we feel very keenly the humanitarian aspect with which your work is conducted, and the chivalrous way in which you, with the medical profession, as a whole, meet these problems of caring for the other 80 per cent; and I think I could almost be voicing the sentiment of the whole public health profession in welcoming you to a closer cooperation with public health officers in solving this problem, which has been brought to you in the paper this morning. If I might center what I have to say upon a definite subject, it would be to urge upon you perhaps even more to familiarize yourselves with the work which the public health profession is doing. It has been my privilege to teach general hygiene to the dentists at Tuft's Dental School for some few years, and at this meeting the Associated Dental Schools have decided that in the extended curriculum, a course in general hygiene will be included.

There are several reasons, it seems to me, why the dentist should extend his knowledge of general hygiene. In the first place, he needs the very latest knowledge of personal hygiene and prophylaxis for his own health, and for the benefit of his patients, because I am sure you men in general practice find that you are asked questions about everything by your patients; more people see you than the medical practitioner. You are a doctor, and you know what the word "doctor" means to the layman; he does not distinguish between the doctor of dentistry and the medical man. He feels perfectly free to ask your advice on questions of hygiene, and if that advise is wisely administered, it is certain that a prescription of proper hygiene may do more for your patient in a great many instances than a prescription of drugs which the physician might give him in correcting the accompanying conditions. This furnishes a definite opportunity for the dentist to exert a wider influence, and increase the esteem of the profession in the eyes of the community. And the community needs this service on the part of the dentist, this responsibility which was so excellently described in Dr. Millberry's paper.

Just what do I mean by getting a little more information? I mean that is seems to me advisable that the dental practitioner should get some of the things we are trying to give our boys over at Tuft's public health organization, a knowledge of the important facts with reference to public health, infection, immunity, the control of water, waste disposal-not that you are to become sanitary engineers, but I believe a man so closely related to the medical profession should have the fundamentals well in hand. The recent discoveries on the qiiestion of personal hygiene and prophylaxis, which I feel in the last four years have made a real science out of that subject, should be well understood.

These calls upon the dental practitioner, these duties in taking care of the other 80 per cent, lead you directly, I believe, to a cooperation with our profession which we heartily welcome; and you will find that the public health profession will not make unreasonable demands on your time. It will try to assist you in establishing that type of dental organization 
which will take care without fees except to the state, only of those people who cannot pay some other way; and it will help you to establish a system whereby you can use the younger members of the profession in taking care of this group of people.

May I urge you to a wider interest and cooperation in the things that we are doing? I might say that I have given a lot of time to this thing within the last few years, because my work in the dental school has prompted me to prepare a concise statement of these fields, particularly for the dental profession, and that is something that has never been done before. There has never been any text or manuscript to which the dentist could turn for a consideration of the public health field from his own viewpoint. (Applause.) I appreciate your kind reception. (Applause.)

\section{John D. Millikin, San Francisco.}

Our profession has been accepting this eighty per cent estimate for many years but no one seems to know where these figures came from. As far as it can be determined, they came about by the publication of the fact that the army dental corps were doing only 20 per cent of the dental work for the soldiers, with one dentist to every 100 enlisted men.

The army had accurate statistics, and at this rate to do only $20 \%$ of the work, it would require 100,000 dentists in the United States to attend to the 100,000,000 people, or twice the number of dentists as are now in the United States.

If you wish to know how well you would care for one thousand patients, ask any army dental surgeon who had tried it. If we were to take one new patient besides our old ones, each day, for 250 working days in a year, each dentist would then be taking care of onefourth as many patients as the army dental surgeon. There would have to be at this rate 400,000 dentists in the United States to do only $20 \%$ of the work.

These figures are given in order to bring to your mind the enormous problem we have before us.

These figures will also show how impossible it is to do the corrective work with the number of dentists we now have or can have in the next generation. It would seem if for no other reason, we should devote our energies to the prevention of dental disease to such an extent that all preventive dentistry could be taken care of by trained hygienists, requiring but a limited amount of skill.

Should this be undertaken, it will require years to furnish enough hygienists. Appreciating that we need more dentists and dental hygienists, it is our duty as dentists to encourage both young men and women to take up this profession.

Dr. Millberry has also called our attention to a fact that we must not overlook, and that is enlarging our offices on a cooperative plan, thus doing more and better dentistry. The close relationship of men and women along the same lines of endeavor will naturally result in increased knowledge. It may be possible that this will not be accepted by the older men of our profession, who may be satisfied with the present conditions, and if such is the case, Dr. Millberry's plan of teaching the dental students along these lines will be necessary, and all dental colleges should take this step at an early date. It may be that should the dentists want young men just entering the profession, and the colleges did not educate them to the value of entering some office for a limited time, that this scheme would fail, so it resolves itself into the urgent necessity of the dentist and the dental colleges entering into the closest cooperation.

Your careful attention is directed towards that part of Dr. Millberry's paper which deals with the Dental Dispensaries. This plan is being adopted to a limited extent in California. This plan provides for young graduates without funds and prevents the drifting dentists 
from entering the offices of the quacks. It provides for the dentist coming from another state who may have failed to obtain his State license and is without funds. It also provides for your patients whom you would like to have receive good dental service, but who are unable to pay for same.

It may be that the organized profession of California knows the value of publicity more than any other state, for the reason that last year we went thru an election campaign when our State dental laws were attacked by one of these dental quacks who spent eighty thousand dollars to get our State dental law changed to suit his style of practice, with the result that the dentists of California had to unite in a publicity campaign at the cost of nearly forty thousand dollars, to offset the intensive advertising campaign offered by that dental quack who had, for years, spent on an average of thirty thousand dollars annually in advertising, while our profession had spent nothing up to the time we found ourselves compelled to.

For those wishing to take up this work, it is suggested that they take Dr. Millberry's conclusions and apply them as their local conditions will permit. (Applause.)

\title{
SUGGESTIVE THERAPY AND TREATMENT OF ABNORMAL CONDITIONS DURING AND FOLLOWING INJECTIONS.
}

\author{
- By P. G. Puterbaugh, M. D., D. D. S., Chicago, Illinois.
}

(Read before the National Dental Association at Its Twenty-third Annual Session, New Orleans, La., October 20-24, 1919.)

$\mathrm{I}^{\mathrm{x}}$ CHOOSING an anesthetic for operative work there is, at present, considerable room for much-needed reform. The time of choosing the anesthetic to fit the operator's convenience, instead of choosing it to fit the operation and the patient should be a thing of the past. Generally speaking, there are two classes of patients viz: those who are with the operator and who are willing to assist; and those who are not. The majority of adult patients may be placed in the former class. Many of the latter class may be placed in the former if a reasonable amount of time and patience be given them in order to engage their interest and cooperation by building up their confidence in the anesthetic and operator before and during the actual operative work.

Those who, from their nervous makeup, persist in remaining in the difficult to control class should have general anesthesia when an anesthesia at all is indicated. This class will also include practically all children under fifteen years of age. Then for the very reason that cooperation of the patient is essential to success in local anesthetic operations, the child and the hysterical, the neurasthenic and the neurotic are to be considered as unfavorable subjects. This does not necessarily imply that local anesthesia is in any way difficult 